Vol. 72, N. ${ }^{\circ}$ II5 (mayo 2020), I5-32

\title{
ECUADOR... 20 AÑOS NO ES NADA: A DOS DÉCADAS DEL MITO DOLARIZADOR
}

\author{
ECUADOR... 20 YEARS ARE NOTHING: TWO DECADES AFTER THE DOLLARIZER MYTH
}

ALBERTO ACOSTA, ${ }^{1}$ JOHN CAJAS-GUIJARRO ${ }^{2}$

1 Investigador independiente, 2 Universidad Central del Ecuador-Flacso, Ecuador

Recepción manuscrito: 19 de abril de 2020

Aceptación versión final: 8 de mayo de 2020

\begin{abstract}
RESUMEN A veinte años de la dolarización de la economía ecuatoriana, el debate sobre tal subordinación monetaria es aún insuficiente. Esto motiva al presente artículo a identificar varias dudas sin resolver que surgen al criticar las narrativas que sostienen al mito dolarizador (medida tomada de forma técnica, falta de alternativas, mayor crecimiento, herramienta contra la hiperinflación, mayor estabilidad, entre otras). Al final, se concluye que un origen histórico trágico y múltiples narrativas cuestionables llevan al país a aceptar una rígida estructura monetaria que llena su economía de incertidumbres.
\end{abstract}

PALABRAS CLAVE Dolarización, salvataje financiero, mito dolarizador, narrativas, incertidumbre.

ABSTRACT Twenty years after Ecuadorian dollarization, there is not enough debate on such a monetary subordination. In response, this paper identifies some unsolved doubts which emerge when the narratives that sustain the dollarizer myth are criticized (technical foundations, absence of alternatives, higher growth, hyperinflation, higher stability, and so on). In the end, the paper concludes that a tragic origin and the multiple questionable narratives make the country to accept a rigid monetary structure that fills its economy with uncertainty.

KEYWORDS Dollarization, financial bailout, dollarizer myth, narratives, uncertainty.

JEL CODES E42, N16, O54.

Nos envejece más la cobardía que el tiempo, los años solo arrugan la piel, pero el miedo arruga el alma.

FACUNDO CABRAL ${ }^{1}$

\section{INTRODUCCIÓN}

Ecuador aún vive el recuerdo de la agresiva devaluación que el sucre sufrió entre 1998 y 1999. Semejante recuerdo, adobado con discursos pesimistas asociados a una desdolarización (Paredes, 2016, pág. 92), ${ }^{2}$ hace que la dolarización se perciba como intocable y capaz de evitar políticas «irresponsables» (White, 2017, pág. 66). Así, emergen los predicadores de la 
dolarización que la defienden incluso afirmando que ésta ha «blindado» al país (Ginatta, 2007), olvidando que el dólar se impuso durante una de las peores crisis sufridas por el Ecuador (Acosta y Cajas-Guijarro, 2017, pág. 90). Por cierto, también hubo beneficiarios, miembros del gran capital -importadores, sectores inmobiliarios, especuladores, grandes empresas de servicios y demás - y estratos altos, previamente bien apertrechados ante la macrodevaluación con la que allanó la dolarización (Acosta, 2000, pág. 24).

Resultado de las pugnas e intereses tras esta discusión, casi no existía ningún debate serio sobre dolarización en el Ecuador antes de ser impuesta. ${ }^{3}$ Incluso, la decisión fue criticada desde múltiples instituciones financieras internacionales (i. e., Chase Manhattan Bank, Merril Lynch), periódicos como The New York Times o The Wall Street Journal, economistas y demás que hablaban de un «salto al vacío» (Luque, 200o, pág. 113). Ahora, a veinte años de la dolarización ecuatoriana, el debate aún es insuficiente: ${ }^{4}$ consideramos que ha quedado algo desactualizada aquella literatura que critique rigurosamente las principales narrativas de quienes defienden la dolarización, provocando que éstas se presenten como «verdades indiscutibles». Ante tal carencia, el presente artículo tiene como objetivo responder — de manera preliminar- a la siguiente pregunta de investigación: ¿Cuáles son algunas de las principales dudas sin resolver dentro del mito dolarizador en el Ecuador a veinte años de su vigencia? Por mito dolarizador, entendemos a un mito que posiciona — desde múltiples narrativas-a la dolarización como una medida que habría traído beneficios y casi ningún perjuicio al país.

Para estudiar al mito dolarizador adoptamos, un enfoque teórico de economía política crítica pues consideramos que hay múltiples grupos de poder que buscan legitimar a la dolarización para posicionar sus intereses particulares como si fuesen intereses nacionales (cf. Gramsci, 1978). En oposición, para nosotros, el mito dolarizador no es verdadero, pues en economía no existen fórmulas mágicas ni medidas invulnerables que siempre den buenos resultados y casi ningún mal efecto; idea que sustentamos en dos niveles: (1) a nivel ontológico, consideramos que la economía es creada por personas que construyen su historia limitadas por circunstancias legadas del pasado (Marx, 2010, pág. 103), provocando que similares medidas aplicadas en momentos históricos diferentes generen resultados distintos (Marx, 2012, pág. 245); y (2) a nivel axiológico, creemos injusto ver a la dolarización como un bien en sí mismo cuando se sostiene en un mito - los cuales abundan en economía-+ resultado de la desesperación de gobernantes corruptos coaligados con grupos de poder en medio de una grave crisis agudizada por el salvataje bancario. Sobre este último nivel, incluso consideramos que la dolarización refleja una "colonialidad monetaria», 7 pues ubica a una moneda foránea de una potencia mundial (dólar) como «superior» a cualquier propuesta monetaria local (Acosta, 2012). Como anota Celso Furtado, «si nos rendimos a la dolarización, retrocederemos a una condición semicolonial» (citado por Bresser Pereira, 2004, pág. 32).

Con estas críticas, no sugerimos salir intempestivamente y a la fuerza de la dolarización, lo cual sería un absurdo, así como fue absurdo dolarizar de golpe e inconsultamente en el año 2000. Lo que pretendemos es identificar varias dudas sin resolver tras el mito para despojar a la dolarización de su velo de poder sobrenatural, entendiéndola más bien como una medida de subordinación monetaria extrema (Guillén Romo, 2005, pág. 90) con la cual el Ecuador ha aceptado (de jure) dotar al dólar estadounidense de todas las funciones del dinero. Así, gran 
parte de la dinámica monetaria ecuatoriana depende de decisiones tomadas en la Reserva Federal: el Estado ecuatoriano se allanó sin condiciones a las políticas norteamericanas - por cierto, decisión en nada comparable a la unión monetaria que originó al euro en Europa, donde al menos se intenta que confluyan las políticas de los países miembros que poseen algún control sobre las decisiones monetarias- ${ }^{8}$

Para identificar algunas dudas sin resolver dentro del mito dolarizador, aplicamos una metodología dialéctica con los siguientes pasos: (1) identificamos algunas narrativas destacadas que defienden la dolarización, (2) confrontamos la veracidad de cada narrativa con evidencia cuantitativa y/o cualitativa de fuentes primarias y secundarias, y (3) como síntesis de la confrontación entre narrativas y evidencia se obtienen varias de las dudas buscadas. Esta metodología posee un alcance explorativo que permite identificar múltiples preguntas específicas que pueden motivar a investigaciones futuras sobre la dolarización en el Ecuador, con la limitación de que en algunos casos el cuestionamiento de las narrativas genera mayores dudas que certezas - lo cual no es una falla en sí mismo-, además que la profundidad de la evidencia puede variar según cada narrativa analizada.

Entre las principales dudas sin resolver identificadas a partir del estudio dialéctico del mito dolarizador, están: el tipo de cambio para dolarizar no se habría obtenido de forma rigurosa, a la vez que la medida tuvo demasiada oposición; al parecer, había alternativas a la dolarización que no se discutieron por intereses particulares; parece que el país no alcanzó un crecimiento económico excepcional luego de dolarizarse en comparación a otros países no dolarizados; quizá la dolarización vuelve a la economía ecuatoriana mucho más frágil a shocks externos; la medida no ha contribuido a mejorar estructuralmente el empleo; la dolarización quizá fue el punto más duro del histórico deterioro de los ingresos de los asalariados. Para llegar a éstas y otras dudas, el artículo se estructura de la siguiente forma: luego de esta introducción, se hace un breve recuento histórico de cómo la dolarización se originó en medio del grave salvataje bancario que Ecuador vivió a fines de los años 90 y se cuestiona la falta de planificación de la medida (siguiente sección); luego, se aplica la metodología dialéctica antes descrita a varias narrativas para identificar múltiples dudas sin resolver a veinte años del mito dolarizador (penúltima sección); finalmente, se concluye que la combinación de un origen histórico trágico y las múltiples dudas de la dolarización llevan al país a sostener un rígido esquema monetario que colma de incertidumbres su economía (última sección).

\section{UNA DOLARIZACIÓN NACIDA ENTRE SAQUEOS E INTERROGANTES}

La dolarización ecuatoriana nació desde la violencia y el saqueo, luego de una transición histórica de una etapa «desarrollista» $\mathrm{y}$ «nacionalista» — a inicios de los años 1970) a una etapa de múltiples ajustes neoliberales — años 1980 y 1990- (Acosta, 2012), similar a cómo sucedería en muchos otros rincones del mundo (Klein, 2007). En el período de ajuste neoliberal, el Estado fomentó la desregulación financiera, como ejemplifica en 1994 la Ley General de Instituciones del Sistema Financiero, impulsada por presión del Fondo Monetario Internacional (FMI). ${ }^{9}$ Gracias a tal desregulación, la banca ecuatoriana se benefició por años de créditos vinculados, malversación de fondos, retiro de dólares hacia el exterior, inversiones en sectores petroleros y en otros negocios 
no bancarios, defraudación de dinero, sucretización de su deuda externa, compra de cuentas especiales en divisas, ${ }^{10}$ ocultamiento y falsificación de información, peculado bancario y demás líos. ${ }^{11}$

Los abusos cometidos gracias a la liberalización financiera llevaron a que, entre 1994 y 1998, quiebren cuatro bancos y siete financieras ecuatorianas — destacándose Banco Continental, Solbanco, Préstamos y Tungurahua-. A tales quiebras se sumaría el contexto del conflicto bélico entre Ecuador y Perú en 1995 y los problemas internacionales por la crisis mexicana (1994), la crisis asiática (1997) y de Brasil y Rusia (1998). Además, el país afrontó un fuerte fenómeno de El Niño en 1998 y un bajo precio del petróleo —el barril de crudo West Texas Intermediate, referencial para el petróleo ecuatoriano, marcó un promedio de USD 12 entre fines de 1998 e inicios de 1999-. Mientras, la estabilidad política se deterioraba en especial desde el efímero Gobierno de A. Bucaram — quien, por cierto, propuso la convertibilidad a 4000 sucres por dólar- ${ }^{12}$

Para fines de 1998, el Filanbanco pasaría a manos del Estado, y desde ahí arrancarían varias quiebras bancarias en cadena afectando en 1999 a otros bancos grandes como Progreso, Popular, Previsora y Pacífico. En respuesta desesperada a la caída del sistema financiero, entre el 8 y el 15 de marzo de 1999, el Ecuador soportó un feriado bancario: se congelaron USD 400o millones impidiendo que los depositantes retiren de la banca sus propios ahorros, a pretexto de evitar corridas monetarias; mientras, estaba ausente la discusión sobre las causas profundas de la crisis financiera. Con ese feriado bancario, perdieron valor las palabras del entonces presidente Jamil Mahuad, quien declararía que «el gobierno jamás va a incautar, jamás va a confiscar las cuentas de nadie». ${ }^{13}$ A su vez, el Estado desembolsó USD 1600 millones buscando el salvataje de instituciones financieras que terminarían quebrando, a más de emitir USD 1400 millones en bonos de la Agencia de Garantía de Depósitos (AGD, creada en 1998 por presión del Banco Mundial): ${ }^{14}$ recursos que ingresaron a una banca que no pagó; de hecho, en la crisis el 70\% de las instituciones financieras privadas quebraron o pasaron al Estado.

Semejantes recursos entregados al sistema financiero para su salvataje empujaron a la drástica devaluación del sucre, como reconocería el propio Banco Central del Ecuador (BCE, 1999). Solo las transferencias del Estado a la banca en problemas, más los bonos emitidos por la AGD, sumaron 15,3\% del producto interno bruto (PIB) de 1999. Tal salvataje presionó a emisiones monetarias agresivas que «licuaron» los recursos de los poseedores de sucres en beneficio de quienes poseían dólares, empezando por la propia banca: entre 1998 y 2000, la emisión desbocada provocó el salto de 5437 a 25.000 sucres por dólar —en el mercado libre de cambios-, restando un 78,3\% del poder adquisitivo de quienes poseían recursos en sucres (BCE, 2017). A la par, con la muerte del sucre, el Ecuador terminó en una crisis generalizada que, según el BCE, habría costado al país unos usD 8600 millones, monto equivalente al 43,8\% del PIB de aquel año — USD 19.635 millones— $-{ }^{15}$ Una crisis en donde se socializó a la población las pérdidas provocadas por las prácticas corruptas, la débil regulación y hasta el exceso de confianza del sistema financiero (Martínez, 2006). ${ }^{16}$

Así, en medio de una crisis generalizada, el domingo 9 de enero de 200o, Jamil Mahuad decretó la dolarización con un tipo de cambio de 25.000 sucres por dólar. Tan popular fue la medida que, a los doce días, Mahuad fue derrocado por fuertes movilizaciones, con participación protagónica del movimiento indígena. ${ }^{17}$ La dolarización se adoptó sin consultar a la población y sin ningún estudio técnico que justifique ni siquiera la tasa de cambio aplicada. 
Veinte años después, Mahuad afirmaría que el tipo de cambio se adoptó con el siguiente procedimiento: «dividimos los dólares que teníamos en la reserva para la cantidad de sucres y de obligaciones que había que considerar, y eso nos dio 25.000 sucres como una medida segura». ${ }^{18}$

Es decir, una de las decisiones económicas más importantes de la historia ecuatoriana, con efectos distributivos abismales, ¡se decidió con una «regla de tres»! Aquí emergen varias dudas sin resolver: ¿no había alguna metodología más rigurosa?, ¿por qué aplicar una tasa de cambio única en vez de aplicar tasas diferenciadas para amortiguar el impacto distributivo?, ¿no debía estimarse cuál sería la pérdida de riqueza e ingresos reales para los tenedores de activos en sucres, así como para asalariados y pensionistas, al menos para diseñar potenciales compensaciones?, ¿se estimaron escenarios que comparen a la dolarización con otras medidas como la convertibilidad o el control monetario por parte del $\mathrm{BCE}$ ?, ¿ $\mathrm{O}$ solo se tomó la medida de forma desesperada como un «salto al vacío»? Las dudas son varias, mientras que los estudios rigurosos son nulos. De hecho, en palabras del entonces presidente subrogante del BCE, Modesto Correa, la dolarización no fue planificada. ${ }^{19}$

A nivel político, también hay dudas. En especial, ¿qué tan legítima podía ser la medida, cuando fue adoptada por un gobierno sin respaldo popular? ${ }^{20}$ Aquí las palabras de Mahuad son claras:

Cuando decido dolarizar, dolarizo sin el Fondo [Monetario Internacional], sin el Banco Central, con la mitad del Congreso desde el centro hacia la izquierda todos en contra, contra los sindicatos, contra la dirigencia indígena, contra un montón de oNG, contra un montón de opiniones de personas ilustres en economía que escribían que era una barbaridad dolarizar, contra todo eso [...] ese rato fue una decisión durísima de tomar porque había un montón de gente en contra. ${ }^{21}$

Con tantas oposiciones, ¿quiénes realmente estaban a favor de dolarizar de golpe sin intentar antes otras medidas? Así es muy difícil ver a la dolarización como una medida de amplio apoyo popular, político y técnico, al menos en el momento de implementarse, y más bien se refuerza la idea de que es un mito sostenido desde narrativas cuestionables.

\section{CRITICANDO ALGUNAS NARRATIVAS DEL MITO DOLARIZADOR}

La dolarización se ha justificado bajo múltiples narrativas: no había alternativas; se debía parar las devaluaciones del sucre; detener la inflación; responder a la «dolarización espontánea»; ganar estabilidad monetaria; reducir las tasas de interés; reactivar la producción; atraer inversión extranjera... y todo alcanzable al instante, como afirmaban los miembros del Foro Económico en un remitido publicado en El Universo el viernes 8 de enero del año 2000.22 Sin embargo, la veracidad de estas narrativas es criticable; al menos, eso sugieren las siguientes puntualizaciones.

\section{HABÍA ALTERNATIVAS}

Es mentira que no había alternativas a la dolarización: existían múltiples posibilidades de enfrentar la crisis ecuatoriana. De hecho, ¿cómo saber que la dolarización era la mejor alternativa para el Ecuador en ese momento sin estudios rigurosos? Incluso, en noviembre de 1999, 
el BCE presentó una Propuesta de Política Económica ante la Crisis (BCE, 1999, pág. 1) donde, en vez de dolarizar, sugería una "política monetaria más activa por parte del Banco Central del Ecuador, que permita retomar el control de los agregados monetarios». Quizá tal propuesta hubiera logrado una estabilización monetaria sin dolarizar: ¿cómo negar tal posibilidad sin un estudio riguroso? Es más, según el mencionado documento se afirma que el propio salvataje bancario complicó la posibilidad del BCE de llevar una política monetaria activa:

El Banco Central del Ecuador ha tenido serias dificultades para esterilizar la emisión [de sucres], que ha crecido a tasas muy altas, por la obligatoriedad asumida de realizar operaciones de reporto con los bonos de la Agencia de Garantía de Depósitos (AGD), y de cumplir con los requerimientos de créditos de liquidez. (вСE, 1999, pág. 1)

En la actual coyuntura económica la política monetaria ha estado endogenizada a la solución de la crisis del sector financiero. (BCE, 1999, pág. 40)

Es decir, el BCE reconoció que el problema monetario a fines de los años 90 tenía entre sus causantes a las emisiones de sucres que el Estado fue empujado a realizar para tratar de salvar al sistema financiero privado. Por tanto, si se limitaba dicha emisión monetaria, quizá hubiera sido posible estabilizar la economía sin dolarizar. Sin embargo, el Gobierno de Mahuad prefirió dolarizar en vez de sanear seriamente al sector financiero y evitar el salvataje vía emisión de sucres. Dentro de ese saneamiento, se pudo hasta nacionalizar el sistema financiero, similar a la propuesta sugerida por Simon Johnson (2009) para la crisis financiera de 2009 en Estados Unidos. Pero en vez del saneamiento, se improvisó a tal nivel que hasta renunció el entonces presidente del directorio del bce, Pablo Better.

Tampoco convence el argumento de que si el Estado no realizaba el salvataje bancario con un drástico incremento de emisiones de sucres, la crisis hubiera sido peor: la crisis debía enfrentarse desde un estudio a fondo de sus orígenes. Si bien dichos orígenes son complejos, es plausible plantear la hipótesis de que el sector financiero tiene un poder político que le permite usar al Estado para socializar sus pérdidas privadas y hasta lucrar de medidas como los salvatajes, ${ }^{23}$ sin importar que ese proceso lleve a la devaluación agresiva del sucre. Si se acepta esa hipótesis, entonces la cuestión de fondo está en enfrentar el poder del sistema financiero y subordinarlo a las demandas del aparato productivo y de la sociedad, no al revés. El caso es que sí había alternativas (ver Tabla 1), pero su instrumentación hubiera requerido enfrentar directamente los intereses de quienes provocaron la crisis y se beneficiaban del salvataje y la dolarización.

\section{EL PROBLEMA DE UNA FALTA DE POLÍTICA CAMBIARIA PROPIA}

La incapacidad del Ecuador de devaluar en dolarización plantea una duda: ¿qué tan «óptimo» - especialmente para fuertes desequilibrios externos y suavizar potenciales shocks externoses tener una moneda que no se puede devaluar según la realidad local, más cuando importantes socios comerciales como Colombia, Perú o Chile mantienen esa capacidad? La propia «teoría económica» plantea que un país debería adoptar la moneda de otro solo si sus ciclos económicos están sincronizados o si hay libre movilidad de factores entre ambos, idea recogida en la hipótesis de las zonas monetarias óptimas de Mundell (1961). Es más, si se revisa la 
Tabla 1. Algunas alternativas planteadas para Ecuador en el año 2000

\begin{tabular}{|c|c|}
\hline Medida & Detalle \\
\hline $\begin{array}{l}\text { Dolarización } \\
\text { oficial o de jure }\end{array}$ & $\begin{array}{l}\text { Una moneda extranjera (dólar) sustituye totalmente a la moneda local y adopta } \\
\text { plenamente las funciones del dinero en el caso oficial (o parcialmente en el caso no } \\
\text { oficial). }\end{array}$ \\
\hline $\begin{array}{l}\text { Caja de } \\
\text { convertibilidad }\end{array}$ & $\begin{array}{l}\text { Tipo de cambio fijo por ley con respecto a una moneda ancla. Se garantiza convertibilidad } \\
\text { automática: el Banco Central debe intercambiar en cualquier momento la moneda local } \\
\text { por el ancla: las reservas del ancla deben igualar o superar a la base monetaria para } \\
\text { fortalecer confianza del público. Se mantiene la moneda local como unidad de cuenta. }\end{array}$ \\
\hline $\begin{array}{l}\text { Control monetario } \\
\text { del BCE sin } \\
\text { salvataje masivo }\end{array}$ & $\begin{array}{l}\text { Establecer metas cambiarias de estabilidad a manejarse con encaje y tasas de interés. La } \\
\text { política de encaje otorgaría premio implícito a transacciones en moneda local. No } \\
\text { debilitar reservas internacionales. Aplicar esterilización monetaria. Redistribuir liquidez } \\
\text { del sistema financiero (incluyendo depósitos del sector público). Usar programación } \\
\text { monetaria y fiscal en momentos que gran porcentaje del sistema financiero se } \\
\text { encontraba bajo control estatal. Replantear la garantía de depósitos para disminuir el } \\
\text { riesgo moral. Reprogramar activos y pasivos de banca y de compañías del sector real. } \\
\text { Establecer prioridades en el gasto y la inversión pública y el financiamiento. Definir nuevo } \\
\text { marco de acción para cuentas offshore. Establecer un flujo máximo de recursos a } \\
\text { disposición de la AGD. Disciplina fiscal. }\end{array}$ \\
\hline $\begin{array}{l}\text { Fondos para } \\
\text { capitalización y } \\
\text { reactivación }\left({ }^{*}\right)\end{array}$ & $\begin{array}{l}\text { Crear fideicomiso (principalmente con financiamiento internacional) para } \\
\text { capitalizar instituciones financieras y reactivar la producción con créditos. } \\
\text { Crear fideicomiso financiado con venta de bonos del Estado para apoyo a } \\
\text { pequeñas y medianas empresas. }\end{array}$ \\
\hline $\begin{array}{l}\text { Política general } \\
\text { de } \\
\text { estabilización }\end{array}$ & $\begin{array}{l}\text { Expansión prudente de demanda agregada. Replanteo de precios relativos, } \\
\text { enfrentando distorsiones entre precios «adelantados» y «retrasados»: unos } \\
\text { deberían aumentarse y otros disminuirse. Manejo estatal estabilizador de } \\
\text { precios como tipo de cambio, salarios mínimos, impuestos indirectos, } \\
\text { precios públicos, tasas de interés, aranceles. }\end{array}$ \\
\hline
\end{tabular}

${ }^{*}$ ) Nota: en la propuesta original del вСE (1999) se sugiere que el fondo también ayude a privatizar instituciones del sistema financiero. Elaboración: propia a partir de Guillén Romo (2005), BCE (1999), Acosta y Schuldt (1999).

historia de cómo múltiples países en el mundo han enfrentado sus crisis financieras (Reinhart y Rogoff, 2009), se notará que la decisión en Ecuador de dolarizar representa un caso sui generis, quizá cercano con Zimbabue - país del cual se habla más adelante-.

La incapacidad de devaluar podría implicar una pérdida de flexibilidad económica y un aumento de la volatilidad de la economía ecuatoriana ante shocks externos. A esto cabe sumar todas las posibles asimetrías que la dolarización podría imponer a la capacidad de aplicar políticas contracíclicas, tal como sugiere Missaglia (2016). Un ejemplo se vivió desde fines de 2014, cuando el dólar estadounidense se apreció fuertemente, encareciendo las exportaciones ecuatorianas en un momento de caída de exportaciones petroleras, a la par que las importaciones se abarataron (Acosta y Cajas-Guijarro, 2018). Aquí se puede recordar, como resultado de la incapacidad de devaluar, a aquella población buscando ingresar a Colombia para comprar aprovechando la devaluación del peso colombiano frente al dólar, ${ }^{24}$ así como la caída económica en ciudades fronterizas - que provocaron protestas en septiembre de 2019 en Carchi, ${ }^{25}$ como antesala a la rebelión de octubre del mismo año-.$^{26}$ 


\section{NO EXISTIÓ HIPERINFLACIÓN}

Sobre la inflación, también hay puntos discutibles. Primero, entre 1993 a 1997 la tasa de inflación anual ecuatoriana mostró un promedio de $27,1 \%$ con una tendencia relativamente estable. Entre 1998-1999 dicha tasa saltó a 43,4 a 60,7\% y - por la propia devaluación-alcanzó un 91,0\% en el año 2000 según el Instituto Nacional de Estadística y Censos (INEC). Es decir, la inflación creció con fuerza en los años de crisis financiera y durante los cuales el Estado otorgaba importantes salvatajes bancarios con drásticas emisiones monetarias. Segundo, la estabilización de precios luego de la dolarización no fue inmediata, pues recién en 2002 la tasa sería menor a dos dígitos $(9,4 \%)$. Tercero, Ecuador nunca vivió una hiperinflación ${ }^{27}$ si se usa, por ejemplo, el umbral de una tasa de 50\% mensual sugerida por Philip Cagan (1956). Según el INEC, los meses que han registrado mayor inflación desde 1969 hasta 2020 son marzo de 1999 con 13,49\% y enero de 2000 con 14,33\%, lejos del límite del 50\%. Para colmo, ningún país latinoamericano que realmente vivió hiperinflación se dolarizó; por ejemplo, para 1985, en Bolivia la inflación anual llegó a 8170,5\% y no se dolarizó. ${ }^{28}$

Asimismo, cabe dudar sobre cuánto de la caída de la inflación ecuatoriana luego del año 2000 se debió realmente a la dolarización y cuánto a la propia estabilización luego de la crisis financiera. Es decir, el país quizá pudo tomar otras medidas de estabilización monetaria, entre ellas detener de inmediato las emisiones de sucres que financiaban el salvataje bancario y realizar un auténtico saneamiento del sector financiero. Si tales medidas se adoptaban, ¿̇ubiera existido hiperinflación? Esta duda no niega que la dolarización ayudó a reducir la inflación, pero quizá su efecto sea menor del que se piensa.

\section{¿GARANTÍA DE ESTABILIDAD?}

Si la dolarización garantiza la estabilización al restringir la política monetaria, ${ }^{29}$ ¿por qué muy pocos países se han dolarizado? En Latinoamérica, los únicos países dolarizados son Ecuador, El Salvador y Panamá - los cuales apenas representaron 2,8\% del PIB de la región en 2018 según la CEPAL.$-^{30} \mathrm{~A}$ su vez, un ejemplo de que la dolarización no necesariamente implica estabilidad es Zimbabue: un país que, ante una importante crisis económica, se dolarizó en 2009. Pero, en vez de estabilidad, la dolarización generó graves complicaciones, siendo quizá la más drástica la escasez de dólares físicos necesarios para las transacciones a causa de los pocos flujos de divisas del país - llegando a registrar grandes aglomeraciones hasta en cajeros-, problema agravado por la frágil capacidad de Zimbabue para acceder a financiamiento externo. ${ }^{31}$ Tales fueron las complicaciones - incluyendo un infructuoso intento de moneda electrónica- que el Ministerio de Finanzas y de Desarrollo Económico del país africano, anunció en 2019 el abandono progresivo de la dolarización, ${ }^{32}$ para lo cual elaboró una planificación de reforma monetaria para el período 2020-2024 buscando implementar una moneda local propia. ${ }^{33}$

Si la dolarización no pudo estabilizar a Zimbabue - aunque los efectos finales aún están en discusión - ${ }^{34}$ y más bien ha generado graves rigideces monetarias al punto de llevar al país a la desdolarización, ¿no podría suceder algo similar al Ecuador, sobre todo cuando el acceso a los mercados financieros internacionales se interrumpa? 
La información disponible vuelve discutible el grado de «espontaneidad» de la dolarización ecuatoriana, la cual más bien parece una respuesta a los peores años de la crisis financiera, al menos en el sector financiero formal: entre 1989 y 1996 la proporción de depósitos expresados en moneda extranjera (principalmente dólares) mostraba un porcentaje promedio estable de 17\%; sería de 1997 a 1999 que los depósitos en dólares crecerían hasta llegar a 53,7\%. Por su parte, para 1999 el 47,4\% del cuasidinero —-depósitos a plazo, certificados de inversión entre otros- y el 66,5\% de la cartera de crédito estaban expresados en dólares (BCE, 2001, pág. 10). Aunque estos indicadores podrían sugerir una «dolarización espontánea» inminente, al compararlos con otros países, el argumento tiembla. Volviendo al caso boliviano, en 1999 el 94\% de los depósitos y el 96,1\% de los créditos estaban expresados en dólares, ${ }^{35}$ proporciones mucho más amplias que en Ecuador y que fueron afrontadas no con dolarización, sino con una «bolivianización». ${ }^{36}$

\section{UNA MEDIDA SOSTENIDA CON «RESPIRADOR ARTIFICIAL»}

A nuestro parecer, la dolarización no se sostuvo por fortalezas intrínsecas. Más bien, el Ecuador ha logrado sostenerla con un «respirador artificial» alimentado por flujos de dólares del exterior recibidos por: exportaciones (sobre todo petroleras), remesas de migrantes, endeudamiento externo y otros flujos. Según información del BCE, entre 2000-2019, al Ecuador ingresaron USD 141,6 mil millones por exportaciones de petróleo crudo, junto con USD 48,9 mil millones de remesas de los migrantes (sobre todo desde España, Estados Unidos e Italia). Ante semejantes magnitudes, cabría preguntarse hasta qué punto la dolarización hubiera sido sostenible sin el extractivismo petrolero y sin la tragedia migratoria que implicó la salida de más de dos millones de compatriotas en la crisis de fines de los 90 - causando una grave descomposición y abandono social- Y Y luego, con el debilitamiento sobre todo de los recursos petroleros, desde fines de 2014 ha crecido vertiginosamente la deuda externa, llegando a USD 41,5 mil millones en 2019. Asimismo, cabría considerar el rol del lavado de dinero: si bien no hay estadísticas oficiales al respecto, ${ }^{37}$ estimaciones preliminares apuntan a que el dinero ilícito podría representar un $4 \%$ del PIB ecuatoriano. ${ }^{38}$

Sobre estas cuestiones, puede revisarse el trabajo de Vernengo y Bradbury (2011, pág. 457), para quienes la dolarización en Ecuador tuvo la «suerte» de que a inicios de los años 2000 el dólar sufrió una importante depreciación —equivalente a una devaluación por sus efectos-, el precio del petróleo creció con fuerza y, en especial, el país ha mantenido importantes remesas. Esto difiere con la convertibilidad argentina que, según los autores, afrontó la apreciación del dólar y la caída de precios de productos primarios (años 90), y al no contar con importantes remesas, debió recurrir a los mercados financieros.

\section{LOS SUPUESTOS RESULTADOS}

En términos económicos, varios países latinoamericanos experimentaron un importante crecimiento en entre mediados de los años 2000 e inicios de los años 2010 alimentado, entre otras razones, por el incremento del precio de varios productos primarios en el período que Svampa (2013) definió como Consenso de los commodities. Dicha tendencia pone en duda de cuán necesaria era la dolarización para que la economía ecuatoriana creciera luego de la crisis de 1999. 
Es más, existe evidencia estadística de que el crecimiento ecuatoriano luego de dolarizarse, al parecer, no fue excepcional en comparación a países similares que no dolarizaron — ver el análisis con control sintético de Yepes (2016) - . Por ejemplo, según datos del Banco Mundial, entre 2000 y 2014, la tasa de crecimiento anual del ingreso por habitante en Ecuador registró un promedio de 2,6\%, nada excepcional si se compara con otros países latinoamericanos: Argentina 1,65\%; Bolivia 2,45\%; Brasil 2,28\%; Chile 3,24\%; Colombia 3\%; Paraguay 1,85\%; Perú 4,3\%; Uruguay 2,89\%; Venezuela 1,43\%. Para colmo, el crecimiento ecuatoriano posdolarización es menor al conseguido durante el primer boom petrolero en los años setenta del siglo pasado: el ingreso por persona creció a un promedio de 4,9\% entre 1974-1978, tasa mayor al 2,6\% conseguido entre 2007-2013 según información del BCE.

A nivel de pobreza, también cabe cuestionar el rol de la dolarización. Según información de la Encuesta de Condiciones de Vida (ECV) del INEC, para 1999 el 52,2\% de la población era pobre, proporción que cayó a 38,3\% en 2006. Sin embargo, esta narrativa omite que para 1995 la pobreza llegó a 39,4\%. Es decir, fue la propia crisis de fines de los años 90 la que incrementó drásticamente la pobreza. Entonces, quizá la reducción de este indicador en los años 2000 antes que ser resultado de la dolarización, podría ser resultado de la superación de los peores años de la crisis: un «efecto rebote» que, como pasó en otros países, posiblemente se pudo lograr sin dolarizar.

Por su parte, la dolarización al parecer no contribuyó a mejorar las condiciones de empleo: en el año 2000 el $68 \%$ de la población económicamente activa (PEA) se encontraba entre el subempleo $(60,82 \%)$ y el desempleo $(7,34 \%)$ según la Encuesta Nacional de Empleo, Desempleo y Subempleo (ENEMDU) del INEC; en cambio, para 2006 la proporción llegó a 71\% de la PEA - con 64,88\% en el subempleo y 6,29\% en el desempleo-. Es más, la dolarización tuvo graves impactos distributivos: en el año 2000, el salario básico llegó a USD 56,7 al mes, monto tan bajo que en 2001 se lo aumentó a USD 121. Otro efecto distributivo infame se vivió para varios pensionistas de la seguridad social: a enero de 2000 unos 145.000 pensionistas recibieron del Instituto Ecuatoriano de Seguridad Social pensiones de solo USD 12,66 al mes, ${ }^{39} \mathrm{y}$ en casos extremos de apenas usD 4 al mes. Así, los ingresos de amplios sectores populares fueron «licuados» por una dolarización cuyo tipo de cambio fue definido con una «regla de tres».

Si bien durante la dolarización se llegó al punto histórico más alto de deterioro salarial, tal tendencia ya se veía — con menos intensidad - años atrás. Según información el BCE, mientras que entre 1975-1980 la participación de los asalariados en el PIв llegaba a un promedio de $30 \%$, para los años 90, y en especial para 1995 esa proporción cayó a 15\% y luego de 1995 la información dejó de publicarse hasta ser retomada en 2007 (Acosta y Cajas-Guijarro, 2017). Así, las décadas de los 80 y los 90 implicaron un deterioro histórico de la participación de las clases trabajadoras en el ingreso; deterioro que, con la dolarización, fue tan drástico que hasta las cuentas nacionales «quebraron».

¿DOLARIZACIÓN COMO PIEZA DE LA TRANSFORMACIÓN NEOLIBERAL?

En su momento, con la dolarización se intentó salvar el gobierno de Mahuad, pero fracasó. Luego, se usó como palanca para facilitar la «transformación neoliberal» impulsada en Ecuador sobre todo desde los años 80 (Acosta, 2012). Esta última opción sigue vigente: varios predicadores de la dolarización -Carlos Julio Emmanuel, Mauro Toscanini, Francisco Swett, Pablo 
Lucio Paredes, entre otros - argumentan que la medida por sí misma no basta si no se complementa con los típicos ajustes neoliberales recomendados para países no dolarizados: ajuste fiscal, reducción del tamaño del Estado, eliminación del déficit, apertura comercial absoluta -incluyendo la firma de la mayor cantidad posible de tratados de libre comercio-, flexibilización laboral - y ambiental- incluso más acentuada que con moneda local (para compensar la incapacidad de devaluar), etc. ${ }^{40}$

Este uso de la dolarización como una pieza más de la narrativa neoliberal crea una peculiar paradoja: bajo la propia lógica neoliberal, si una economía aplica la receta de total liberalización manteniendo su moneda propia y dejando que su cotización fluctúe libremente en el mercado, ¿por qué necesitaría dolarizarse? Es más, bajo la misma lógica, ¿no es contrario a la libertad económica que el Estado imponga a la población el uso de una moneda extranjera? Nótese que F. Hayek sugería que cada individuo debería tener el derecho a libremente escoger el dinero que desee usar en sus transacciones (Hayek, 1976). Para colmo, M. Friedman afirmaría en una entrevista en Forbes en 1997 que «la moneda es un símbolo muy importante de soberanía. Y me parece que una nación, si va a seguir siendo una nación, necesita tantos símbolos de soberanía como sea posible». ${ }^{41}$ Con estas ideas no se busca hacer una apología a estos autores, sino mostrar las posibles contradicciones que emergen cuando la dolarización entra en la narrativa neoliberal.

\section{CONCLUSIÓN: TRAGEDIA, INCERTIDUMBRE... Y MIEDO}

A partir de la crítica dialéctica aplicada a varias de las narrativas que sostienen el mito dolarizador, hemos identificado varias dudas sin resolver. Quizá las más importantes son: (1) en medio de la grave crisis financiera de fines de los años 9o, el tipo de cambio para dolarizar no se habría obtenido de forma rigurosa, a la vez que la medida tuvo demasiada oposición y nulo respaldo técnico; (2) al parecer, había alternativas a la dolarización que no se discutieron por intereses particulares e incluso podría afirmarse que la dolarización no fue planificada; (3) el país no vivía hiperinflación al momento de dolarizar, y quizá el efecto de la medida sobre la inflación sea menor al que se imagina; (4) quizá la dolarización vuelve a la economía ecuatoriana mucho más frágil a shocks externos, generando efectos negativos en la estabilidad económica, e incluso con el riesgo de generar rigideces monetarias que pueden empujar hasta a la desdolarización (como en Zimbabue); (5) ni los niveles más altos de «dolarización espontánea» en el Ecuador igualaron a los niveles de otros países que no necesitaron de la dolarización para reducirlos (como Bolivia); (6) la dolarización ecuatoriana no parece sostenerse en sí misma, sino que es altamente dependiente de flujos externos, lo cual puede volver al país en extremo dependiente sobre dodo del endeudamiento externo; (7) parece que el país no alcanzó un crecimiento económico excepcional luego de dolarizarse en comparación a otros países no dolarizados; (8) el efecto sobre la pobreza es dudoso dadas las distorsiones causadas por la crisis financiera; (9) la medida no ha contribuido a mejorar estructuralmente el empleo; (10) la dolarización quizá fue el punto más duro del histórico deterioro de los ingresos de los asalariados — tendencia que se venía arrastrando a lo largo de la «triste noche neoliberal»—; (11) la defensa de la dolarización parece generar contradicciones cuando se la inserta en la narrativa neoliberal. 
Es todo este complejo conjunto de dudas sin resolver de la dolarización el que, creemos, debería tomarse en cuenta luego de dos décadas de implementarse la medida; dos décadas en donde el país parece encontrarse atorado en una incertidumbre monetaria que se ha intentado sostener por años a través de un irresponsable endeudamiento externo (Acosta y CajasGuijarro, 2018). Incertidumbre que se ha complicado todavía más gracias a la crisis humanitaria - y económica- provocada por el coronavirus.

Mientras la dolarización parece sobrevivir con extractivismo, remesas y sobre todo con deuda en los últimos tiempos, las condiciones concretas de su dinámica en la economía ecuatoriana están repletas de incertidumbres en temas como el manejo de reservas. Por un lado, el progresismo correísta desperdició en una inexistente transformación productiva los importantes flujos de dólares que obtuvo el Ecuador durante el Consenso de los commodities y estaban alimentando a las reservas internacionales. Por otro lado, el neoliberalismo morenista solo sostiene dichas reservas para brindar seguridad a los mercados financieros internacionales en el pago de deuda. En el país no se observa un intento claro de consolidar un manejo de reservas en dolarización que defina cuáles podrían ser los requerimientos para garantizar el normal funcionamiento de la liquidez interna y proveer al Estado de un potencial instrumento de política económica contracíclica. Tal es así que, en respuesta a la crisis del coronavirus vivida en 2020, el gobierno ecuatoriano ha debido apelar a la creación de fondos de emergencia y a mayor endeudamiento externo para obtener una liquidez que le permita hacer frente tanto a gastos de salud como a subvenciones directas a sectores deprimidos.

Esta cuestión es crucial pues parte importante de los estudios sobre dolarización encuentran como uno de sus defectos que la medida quita al país las capacidades de reaccionar ante shocks externos por medio de política monetaria, provocando mayor volatilidad e inestabilidad económica ${ }^{42}$ Es decir, la dolarización quitaría a un país la capacidad de ajustarse a la volatilidad externa. Por ejemplo, ante una caída en el precio del petróleo - como el colapso petrolero de 2020 - , en una economía como la ecuatoriana, eso implica una fuerte contracción en los ingresos fiscales, lo cual obliga a generar un ajuste del gasto público a la baja y, por tanto, tiende a reducirse la actividad económica si no hay un fondo de estabilización que suavice el impacto. ${ }^{43}$ Igualmente existen importantes presiones fiscales por la pérdida que sufre el Estado de su poder de generar - y redistribuir - recursos vía financiamiento propio con emisión monetaria $-\mathrm{y}$, en menor medida, a través del señoreaje—. ${ }^{44}$ Además, el país posee la tendencia estructural a expulsar dólares por sus necesidades de importación — sobre todo de insumos para la producción-, lo cual puede afectar la liquidez interna.

A más de estas rigideces, la propia liquidez del Ecuador vive en la incertidumbre por múltiples factores: potenciales distorsiones causadas por la apreciación del tipo de cambio real al estilo de la enfermedad holandesa - ${ }^{45}$ que podrían volverse más difíciles de identificar que cuando existe moneda local; una «dependencia mutua» entre liquidez y balanza de pagos haciendo que la red de transacciones monetarias dependa de la red de transacciones con el resto del mundo-; la posibilidad de que el efecto multiplicador del gasto autónomo sea diferente en una economía con moneda local comparada con una economía dolarizada; ${ }^{46}$ dificultades para conocer la real cantidad de dólares físicos en circulación —que, al parecer no logra ser plenamente identificable con las metodologías convencionales de estimación de agregados 
monetarios-; una elevada informalidad de la economía causante de que buena parte de las transacciones dependa de la disponibilidad y flujo de dólares físicos; y hasta las nuevas formas que adquiere la política monetaria en dolarización, especialmente con la creación endógena de dinero a través del crédito bancario - así como con el impulso de medios de pago alternativos- ${ }^{47}$

A todas estas incertidumbres cabe agregar la preocupante tendencia que vive el Ecuador aproximadamente desde 2016 con tasas de inflación muy bajas y en varios casos hasta negativas, lo cual plantea un posible vínculo entre dolarización y deflación en períodos de estancamiento prolongado ${ }^{48}$ - contrastando con épocas de expansión en las cuales la inflación ecuatoriana superaba a la inflación en Estados Unidos-. También cabría estudiar la sostenibilidad de la dolarización en épocas de crisis combinadas con excesivos y persistentes márgenes de ganancia (varios de carácter oligopólico) incluso en la actividad financiera (con tasas de interés muy altas pese a la dolarización).

Entre incertidumbres y dudas sin resolver, surge el ambiente perfecto para que el mito dolarizador y el miedo domine en el imaginario colectivo. Como resultado, emerge en varios sectores el miedo de que el mero cuestionamiento de la dolarización despierte a los fantasmas de una crisis igual o hasta peor que la crisis de fines de los años 9o. Sin embargo, ese miedo monetario encierra una paradoja: es justo la falta de crítica y discusión la que puede provocar que la dolarización colapse junto con toda la economía ecuatoriana, peor aún en un contexto de crisis generalizada como la que arrancó en 2020 a causa de la pandemia del coronavirus.

En definitiva, la sostenibilidad de la dolarización en sí misma no puede ni debe verse como el objetivo de la economía. El objetivo de la economía debería ser el bienestar humano, mientras que la política monetaria solo es un instrumento. Penosamente en una sociedad como la capitalista, donde el poder económico, político, mediático y de muchos otros tipos se concentra en pequeños grupos no democráticos, los mitos económicos se vuelven un dispositivo más para sostener el statu quo y sostener esas diferentes formas de poder -el propio manejo de dinero implica un ejercicio de poder-. Si llegan a combinarse circunstancias monetarias adversas para el país, como en efecto ha sucedido desde 2020, es mejor estar preparados sin miedo, sin dogmas, sin nuevamente permitir que se atraque a los sectores populares con crueles juegos cambiarios. Si en algún momento es necesario superar la dolarización -o al menos flexibilizarla - es necesario hacerlo en orden y, sobre todo, de forma democrática. Caso contrario, el saqueo y el trauma de 1999 podrían repetirse si los grupos de poder llegan a necesitarlos.

\section{NOTAS}

1 Agradecemos a Jürgen Schuldt y a dos evaluadores anónimos por sus comentarios a este artículo.

2 Lucio Paredes (2016, pág. 92) afirma que «el principal freno a la salida de la dolarización parece ser lo difícil del proceso y la enorme inestabilidad que generaría - todos los ajustes ante shocks externos son complejos, en dolarización aún más; pero incluir la desdolarización en el paquete parece muy costoso». 3 Como ejemplo, ver López Buenaño (1999).

4 Algunas referencias para reconstruir el debate son Acosta (2001), Acosta (2004), Cajas-Guijarro y Martínez (ed.) (2016), Acosta y Juncosa (comp.) (2000), Larrea (2004), Marconi (ed.) (2001), Correa (2004), Paredes (2017), Lucio Paredes (2000), Naranjo (2005) entre otras. 
5 Sobre estas concepciones ontológicas, ver Cajas-Guijarro (2018).

6 Sobre la cuestión de los mitos en economía (aplicada al caso del libre comercio) se puede revisar el trabajo de Cajas-Guijarro (2018).

7 Como manifestación particular de la «colonialidad del poder» sugerida por Quijano (1999).

8 Para una reseña crítica sobre la crisis del euro, ver Guillén Romo (2017).

9 Por ejemplo, antes de aprobarse dicha ley, los técnicos de la Superintendencia de Bancos revisaban directamente la contabilidad de las instituciones financieras; luego, la supervisión se basó en información remitida por los propios bancos (Mesías, 2002, pág. 70).

10 Sobre la sucretización, ver Acosta (1994).

11 Algunos detalles sobre los casos de Filanbanco, Banco de Préstamos y Banco del Progreso se los puede encontrar en trabajo de Salguero Llanos (2005, págs. 153-154).

12 Sobre convertibilidad en medio de la crisis ecuatoriana, ver Gallardo (1999). Hasta se podría plantear la hipótesis que el gobierno de Mahuad — aliado con el Partido Socialcristiano- dolarizó, entre otras razones, para negar la propuesta de convertibilidad de A. Bucaram.

13 Declaración disponible en https://bit.ly/2zgztxv

14 Sobre el rol del Banco Mundial en la desregulación financiera ecuatoriana en los años 9o, ver Comité para la Abolición de las Deudas Ilegítimas (CADTM, 2008).

15 Datos citados por El Telégrafo: «La quiebra de la banca y congelación de cuentas costaron 8.600 millones». Disponible en https://bit.ly/2RKtJyE

16 Para un análisis de la economía política de la crisis financiera ecuatoriana, ver Martínez (2006).

17 Si bien Mahuad decretó la dolarización, su implementación se aprobó vía ley el 22 de febrero de 2000 en el Gobierno de Gustavo Noboa.

18 Declaración disponible en https://bit.ly/2ylpzq9.

19 El Universo: «Modesto Correa dice que la dolarización en Ecuador no fue planificada». Disponible en https://bit.ly/2zcDsye

20 El 10 de enero de 2000, la empresa CEDATOs consultó a la población sobre la dolarización: solo $37 \%$ entendía la medida; $13 \%$ dijo que manejó alguna vez dólares; y 32\% consideraban a la medida como favorable, pero se manifestaba altamente confundida. Ver nota de Ecuador Inmediato disponible en https://bit.ly/2ynelyj

21 Declaración disponible en https://bit.ly/2RQK4C5

22 Como ejemplo, ver la entrevista dada por José Luis Cordeiro en El Universo el 24 de febrero de 2000, donde menciona que la dolarización «no es la cura de todos los males, no va a acabar con el sidA, pero sí sentará las bases para que la economía pueda crecer [...] la medida se debe aprobar porque es tan poderosa, que por sí sola comienza a hacer girar las ruedas de la reactivación económica».

23 Akerlof y Romer (1993) plantean un modelo teórico donde los agentes pueden identificar como «óptimo» elegir un proyecto destinado a la quiebra si saben que pueden cargar las pérdidas al Estado y éste les otorga algún tipo de salvataje. Para ilustrar el argumento, Akerlof y Romer mencionan la crisis financiera de Chile a inicios de los años 8o, así como algunas crisis financieras en los Estados Unidos en la misma década, especialmente la «crisis de ahorros y préstamos».

24 Ver El Comercio: «Dólar alto en Colombia atrae a ecuatorianos, para compras». Disponible en https://bit.ly/2хкibpo

25 Ver El Mercurio: «Con sexto día de protestas consecutivas el Carchi exige atención del Gobierno». Disponible en https://bit.ly/3alNG5s

26 Para una reseña de la rebelión de octubre de 2019, ver Acosta y Cajas-Guijarro (2020).

27 Sobre cómo el Ecuador no se encontraba en hiperinflación - y quizá no había condiciones para que suceda a futuro-, ver Acosta y Schuldt (2000) y Schuldt y Acosta (1995 cap. 3).

28 Datos disponibles en Morales (1986, pág. 4).

29 Mantenemos la hipótesis de que, aun en dolarización, es posible ejercer alguna "política monetaria» vía crédito, bonos, manejo de reservas, tasas de interés, deuda externa, entre otros instrumentos.

30 En el caso panameño la dolarización lleva más de 100 años a raíz de la construcción del canal interoceánico y de las presiones de los Estados Unidos que separaron Panamá de Colombia en 1903. 
31 Para una reflexión al respecto - discutible en algunos puntos-, ver el artículo del American Institute for Economic Research: «Why dollarization doesn't work in Zimbabwe», agosto 9, 2019. Disponibe en https://bit.ly/2zaHnel

32 Ver la nota de prensa del Ministerio de Finanzas y Desarrollo Económico de Zimbabue disponible en https://bit.ly/2wFGsdz

33 Dicho plan se encuentra disponible en https://bit.ly/2zkyyic

34 Para un análisis estadístico entre dolarización y crecimiento en Zimbabue, ver Pasara y Garidzirai (2020).

35 Ver Patiño (2003, pág. 83).

36 Ver Molina (2019).

37 Ver Primicias: «El Banco Central quiere saber cuánto dinero se lava en el país». Disponible en https:// bit.ly/2whsBoI

38 Dato difundido en La Hora: «Más de \$4 mil millones del PIB en dinero ilícito». Disponible en https:// bit.ly/2zja2I2

39 Ver El Comercio: «Los jubilados sortean dolores y buscan nuevas actividades». Disponible en https:// bit.ly/3bpdn6y

40 Ver Expreso: «La deuda con la dolarización». Disponible en https://bit.ly/2vH787h

41 Ver Forbes: «Milton Friedman: beware the funny money». Disponible en https://bit.ly/3eaooae

42 Ver Duncan (2003), Edwards e Magendzo (2003), Roubini y Setser (2003).

43 Para el contexto venezolano, ver Vera (2018).

44 Para una estimación del señoreaje perdido por Ecuador desde la dolarización, ver Calle y Wong (2020).

45 Ver Schuldt (1994).

46 Esto quizá a causa de que el gasto autónomo hecho en dólares puede salir de la economía con mayor facilidad y sin generar transacciones internas en comparación al gasto autónomo hecho con moneda local —el cual, necesariamente para salir de la economía, requeriría de su conversión en dólares-.

47 Ver Schuldt y Acosta (2017).

48 Para revisar estas y otras incertidumbres, ver Acosta y Cajas-Guijarro (2018, págs. 230-248).

\section{REFERENCIAS}

Acosta, A. (1994). Los nombres de la deuda: sucretizadores, canjeadores y tenedores. Quito, Ecuador: FONDAD-CAAP.

Acosta, A. (2000). La trampa de la dolarización. Mitos y realidades para la reflexión. En A. Acosta y J. E. Juncosa (eds.), Dolarización. Informe urgente, (9-46). Quito, Ecuador: ILDIs y Abya Yala/UPs.

Acosta, A. (2004). Dolarización o desdolarización: ¡ésa no es toda la cuestión! Íconos Revista de Ciencias Sociales (19), 54-65.

Acosta, A. (2012). Breve historia económica del Ecuador. Quito, Ecuador: Corporación Editora Nacional.

Acosta, A. (marzo, 2001). El falso dilema de la dolarización. Nueva Sociedad 172, 66-84.

Acosta, A. y Cajas-Guijarro, J. (2017). Con el correísmo de regreso al W. C. Una primera lectura al ciclo capitalista de la economía ecuatoriana entre 200o-2014. En Desafíos del pensamiento crítico: Memorias del Décimo Congreso Ecuatoriano de Sociología y Política. Quito, Ecuador: Universidad Central del Ecuador.

Acosta, A. y Cajas-Guijarro, J. (2018). Una década desperdiciada. Las sombras del correísmo. Quito, Ecuador: Centro Andino de Acción Popular.

Acosta, A. y Cajas-Guijarro, J. (2020). Rebelión en los andes: ecos económico-políticos del levantamiento popular ecuatoriano. En N. Martínez (ed.), Octubre (149-186). Quito, Ecuador: El árbol de papel. 
Acosta, A. y Juncosa, J. (200o). Dolarización. Informe urgente. Quito, Ecuador: ILDIs y Abya-Yala/Ups. Acosta, A. y Schuldt, J. (1999). La hora de la reactivación. El mito de la falta de alternativas. Quito, Ecuador: ILDIS Y ESPOL.

Acosta, A. y Schuldt, J. (2000). ¿Dolarización: vacuna para la hiperinflación? Ecuador Debate (49), 25-41.

Akerlof, G. A. y Romer, P. (1993). Looting: the economic underworld of bankruptcy for profit. Brookings papers on economic activity, 24(2), 1-74.

Banco Central del Ecuador (BCE). (1999). Propuesta de política económica ante la crisis. Recuperado de https://contenido.bce.fin.ec/documentos/PublicacionesNotas/Catalogo/Apuntes/aeo7.pdf

Banco Central del Ecuador (вСE). (2001). La dolarización en el Ecuador. Recuperado de https://contenido.bce.fin.ec/documentos/PublicacionesNotas/Notas/Dolarizacion/pdf/Cabezas et al.pdf

Banco Central del Ecuador (BCE). (2017). Noventa años del Banco Central del Ecuador. Series estadísticas históricas. (s. d.).

Bresser P. y Carlos, L. (2004). Método y pasión en Celso Furtado. Revista de la CePAL. (s. d.).

Cagan, P. (1956). The monetary dynamics of hyperinflation. In M. Friedman, Studies in the Quantity Theory of Money (25-117). Chicago, UsA: Universisty of Chicago Press.

Cajas-Guijarro, J. (2018). Los capos del comercio. Concentración, poder y acuerdos comerciales en el Ecuador: un preludio. Quito, Ecuador: Plataforma por el Derecho a la Salud/Fundación Donum/Fos.

Cajas-Guijarro, J. (2018). Materialismo histórico-dialéctico: una crítica a sus fundamentos. Filosofía de la Economía, 7(2), 137-155.

Cajas-Guijarro, J. y Martínez, A. (eds.) (2016). Teoría y experiencia de una dolarización en crisis. Revista Economía, 68, (s. d.).

Calle, E. J. y Calle Wong. F. (2020). Estimación financiera del señoreaje perdido por el Ecuador desde la dolarización. Centro Sur 4(1). (s. d.).

Comité para la Abolición de las Deudas Ilegítimas (CADTM). (2008). Los préstamos envenenados del Banco Mundial a Ecuador. Alegación para conseguir su repudio. Recuperado de http://www. cadtm.org/spip.php?page=imprimer\&id_article $=3507$.

Correa, R. (2004). Dolarización y desdolarización: más elementos para el debate. Íconos Revista de Ciencias Sociales, 20, 84-69.

Duncan, R. (2003). Exploring the implications of official dollarization of macroeconomic volatility. Documento de trabajo. Banco Central de Chile.

Edwards, S. y Magendzo, I. (2003). Strict dollarization and economic performance: an empirical investigation. National Bureau of Economic Research.

Escobar P. (2003). Efectos de las variaciones del tipo de cambio sobre las actividades de intermediación financiera de Bolivia: 1990-2003. Revista de Análisis del Banco Central de Bolivia, 6, 73.

Gallardo, J. (1999). El mito de la convertibilidad. Guayaquil, Ecuador: ESPOL.

Ginatta, J. H. (2007). Dolarización. Un país blindado. Guayaquil, Ecuador: Edino.

Gramsci, A. (1978). Selections from prision notebooks. London, UK: Lawrence \& Wishart.

Guillén Romo, H. (2005). La caja de convertibilidad, la dolarización y la integración monetaria en América Latina. Economía unam, 2(6), 72-101.

Guillén Romo, H. (2017). La construcción monetaria europea y la crisis del euro: la perspectiva de la izquierda radical griega. Economía UnAM, 14(40), 13-47.

Hayek, F. (1976). Choice in currency. A way to stop inflation. London, UK: Institute of Economic Affairs. 
Johnson, S. (2009, may). The quiet coup. The Atlantic. Recuperado de https:/www.theatlantic.com/ magazine/archive/2009/05/the-quiet-coup/307364/

Klein, N. (2007). The shock doctrine: the rise of disaster capitalism. New York, usa: Henry Holt and Company. Larrea, C. (2004). Dolarización, crisis y pobreza en el Ecuador. Quito, Ecuador: ILDIs, Abya Yala.

López Buenaño, F. (1999). Por qué y cómo dolarizar. Guayaquil, Ecuador: ESPOL.

Luque, A. (2000). Dolarización. El salto al vacío. En A. Acosta y J. E. Juncosa (eds.), Dolarización. Informe urgente, (113-56). Quito, Ecuador: ILDIs y Abya Yala/ups.

Marconi, S. (ed.) (2001). Macroeconomía y economía política en dolarización. Quito, Ecuador: Abya Yala/ UPS-ILDIS-UASB.

Martínez, G. X. (2006). The political economy of the Ecuadorian financial crisis. Cambridge Journal of Economics, $30(4), 567-585$.

Marx, K. (2010 [1852]). The Eighteenth Brumaire of Luis Bonaparte. In K. Marx, Marx \& Engels. Collected Works (99-197). New York, USA: Lawrence \& Wishart.

Marx, K. (2012 [1877]). Carta a la redacción del Otetschestwennyje Sapiski. En C. Rendueles (ed.), Karl Marx: Escritos sobre materialismo histórico. Madrid, España: Alianza Editorial.

Mesías, A. (2002). La crisis bancaria de 1999: un análisis a partir de la teoría de información asimétrica. Cuestiones Económicas, 18(2:3), 69-171.

Missaglia, M. (2016). Dollarization: some theoretical preliminary thoughts. Revista Economía, 68(108), 59-73.

Morales, J. A. (1986). Crisis y política económica en Bolivia de 1982 a 1985. Documento de trabajo. La Paz, Bolivia: Universidad Católica Boliviana.

Mundell, R. A. (1961). A theory of optimum currency areas. The American economic review, 51(4), 657-665.

Naranjo, M. (2005). Dolarización oficial y regímenes monetarios en el Ecuador. Quito, Ecuador: Colegio de Economistas de Pichincha.

Paredes, G. (2017). Ecuador: ¿por qué salir de la dolarización? Revista de la CEPAL, (121), 149-67.

Paredes, P. L. (2000). El libro de la dolarización. Lo que todos deben saber. Quito, Ecuador: Megagraph.

Paredes, P. L. (2016). La dolarización más allá de la estabilidad monetaria. Revista Economía, 68(108), 75-95.

Pasara, M. T. y Garidzirai, R. (2020). The boomerang effects: An analysis of the pre and post dollarisation era in Zimbabwe. Economies, 8(2), 32.

Quijano, A. (1999). Colonialidad del poder, cultura y conocimiento en América Latina. Dispositio, 24(51), 137-148.

Reinhart, C. M. y Rogoff, K. (2009). This time is different: eight centuries of financial folly. Princeton, UsA: Princeton University Press.

Roubini, N. y Setser, B. (2003). Should Iraq dollarize, adopt a currency board or let its currency float? A policy analysis.

Salguero Llanos, M. (2005). La crisis bancaria de 1999 en el Ecuador: un análisis a partir del Cuadro de Operaciones Financieras (COF) y la matriz de flujo de fondos de «quién a quién». (Tesis de Maestría). Flacso, Quito, Ecuador.

Schuldt, J. (1994). La enfermedad holandesa y otros virus de la economía peruana. Documento de trabajo. Lima, Perú: Universidad del Pacífico.

Schuldt, J. y Acosta, A. (1995). Inflación: enfoques y políticas alternativos para América Latina y el Ecuador. Quito, Ecuador: Libresa. 
Schuldt, J. y Acosta, A. (2017). De la dolarización oficial a la moneda propia. Una propuesta para Ecuador. Documento de trabajo. Centro Interdisciplinario para el Estudio de Políticas Públicas.

Svampa, M. (2013). «Consenso de los commodities» y lenguajes de valoración en América Latina. Nueva Sociedad, (244), 30-46.

Vera, L. (2018). ¿Por qué la dolarización puede no ser una buena idea para Venezuela? Prodavinci. Recuperado de https://prodavinci.com/por-que-la-dolarizacion-puede-no-ser-una-buena-ideapara-venezuela/

Vernengo, M. y Bradbury, M. (2011). The limits to dollarization in Ecuador: lessons from Argentina. Journal of World-Systems Research, 17(2), 457-462.

White, L. (2017). Dolarización y libertad monetaria. Polémika, 11, 61-8o.

Yepes, J. (2016). Dollarization and growth: A synthetic control approach to Ecuador and El Salvador's cases. (Tesis de Maestría). Universidad de Baylor, Texas, usA. 